\title{
Comunicata Scientiae: a horticulture journal
}

\author{
Ítalo Herbert Lucena Cavalcante \\ Editor of Comunicata Scientiae
}

Comunicata Scientiae is a scientific journal created at the Campus "Prof.a Cinobelina Elvas" of the Federal University of Piauí in 2009, which had the first issue published in 2010.

Initially, the journal aimed to disseminate the knowledge generated by the scientific community through the publication of research results and new scientific proposals unpublished and relevant to the Agrarian and Environmental Sciences. With this proposal, the journal had a significant growth in the proposed knowledge areas (Agrarian and Environmental Sciences) and it was indexed in the main databases of the world as SCOPUS (Elsevier), obtaining SJR already in 2011 of 0,187 , a value that is currently 0.372 , which includes it in the second best category of SCOPUS, the Q2.

However, in 2012, the journal was submitted to ISI coverage to obtain the JCR, and the response from that database was that the area in which the journal was inserted (Agrarian and Environmental Sciences) was already well attended in our geographic region. Since then we have evaluated the possibility of redefining its coverage area and, due to several other relevant factors, we believe that it is moment of consolidating this structural change.

In this sense, we gratefully thank all researchers worldwide who submitted, evaluated and published their research results in Comunicata Scientiae, which without them this journal would not have reached the level consolidated today.

On the other hand, we announce that from April 2019 Comunicata Scientiae will become an exclusive journal of HORTICULTURE, receiving submissions only of unpublished manuscripts and research notes whose object of study is fruit, vegetable and/or ornamental plants species. This change of scope aims to direct submissions to the editors' specific area, speeding up the evaluation process, promoting evaluations only by experts on the subject of the submission, and consequently, a shorter time between the manuscript submission and the respective evaluation. In parallel, the new area of expertise will position the journal where currently few journals exclusively operate, highlighting in Brazil the Brazilian Journal of Fruticulture (formally Revista Brasileira de Fruticultura), Ornamental Horticulture and Brazilian Journal of Horticulture (formally Revista Brasilera de Horticultura), and will highlight Comunicata Scientiae as the first Brazilian scientific journal of HORTICULTURE, involving exclusively fruit, vegetable or ornamental species.

So, we invite everyone to participate in this new journal proposal, which will continue with the same principles that have always been guiding work, dedication and unity, but now publishing quality science only in HORTICULTURE. 